\title{
Quick regional centroid moment tensor solutions for the Emilia 2012 (northern Italy) seismic sequence
}

\author{
Silvia Pondrelli ${ }^{1, \star}$, Simone Salimbeni ${ }^{1}$, Paolo Perfetti, Peter Danecek ${ }^{2}$ \\ ${ }^{1}$ Istituto Nazionale di Geofisica e Vulcanologia, Sezione di Bologna, Bologna, Italy \\ ${ }^{2}$ Instituto Andaluz de Geofisica, Universidad de Granada, Campus Universitario de Cartuja, Granada, Spain
}

\author{
Article history \\ Received July 24, 2012; accepted September 14, 2012. \\ Subject classification: \\ Earthquake source, Seismic moment tensor, Wave analysis, Data processing.
}

\section{Introduction}

Seismic moment tensors are one of the most relevant pieces of information about earthquakes for the present day. The moment magnitude, $\mathrm{M}_{\mathrm{W}}$, is derived from the seismic moment tensor, and is considered worldwide as the standard measure of earthquake dimensions. From the moment tensor, or its best double couple, i.e., the focal mechanism, it is possible to immediately understand the tectonic style, and thus the kind of activated fault. The computation of the moment tensor immediately after an earthquake has occurred can be used to rapidly provide shaking distributions, eventually including it in a shaking map computation, or it can be used in source propagation studies to infer the presence of rupture directivity.

Over the last 15 years, regional centroid moment tensors (RCMTs) have been computed regularly and have contributed to the European-Mediterranean RCMT catalog [Pondrelli et al. 2002, 2004, 2006, 2007, 2011] (http:/ /www. bo.ingv.it/RCMT). The RCMT is obtained by inverting for intermediate surface waves filtered in the interval of $35 \mathrm{~s}$ to $60 \mathrm{~s}$ as a function of the magnitude; body waves are also included in the inversion, when favorable, and they are modeled separately, but simultaneously [Pondrelli et al. 2011]. Seismograms recorded at regional distances contain the best signals to invert for the source parameters of moderate magnitude earthquakes. For greater magnitude events, data from much more distant stations are also used. Body waves are modeled by summation of the Earth normal modes added with three-dimensional heterogeneous mantle structure [Woodhouse and Dziewonski 1984], while for surface waves, global phase velocity maps are used [Ekström et al. 1997].

During the last few years, we have developed an automatic python procedure, named Pypaver, which helps to shorten the Quick RCMT (QRCMT) computation times [Pondrelli et al. 2012], and it was successfully used during the Emilia 2012 (northern Italy) seismic sequence. In this study, we first show our QRCMT solutions, and then we describe the motivation for wide use of automatic procedures. We also explain why a manual review of seismic moment tensor solutions for most earthquakes analyzed is still preferred before publication. Indeed, the evidence that QRCMTs are stable solutions is given by the comparison with seismic moment tensors produced by other agencies and with other computation methods.

\section{Quick RCMT solutions for the Emilia seismic sequence}

During the night between May 19 and 20, 2012, the Emilia region (northern Italy) started to be shaken by a seismic sequence. The first major event, of $\mathrm{M}_{\mathrm{L}} 5.9\left(\mathrm{M}_{\mathrm{W}} 6.1\right)$ that occurred at 02:03 UTC time was preceded by a $\mathrm{M}_{\mathrm{L}} 4.1$ $\left(\mathrm{M}_{\mathrm{W}} 4.3\right)$ earthquake, about $2 \mathrm{~h}$ before. During the same night, several events with $\mathrm{M}_{\mathrm{L}}$ between 4.5 and 5.1 also occurred (http:/ / iside.rm.ingv.it/) [see other reports in this Annals of Geophysics special volume]. The seismic sequence had another increase in activity on May 29, 2012, with a $M_{L} 5.8\left(M_{W}\right.$ 5.9) event in the morning, at 07:00 UTC, followed by two events with $M_{L} 5.3$ and 5.2, one at 10:55 UTC and the other $5 \mathrm{~min}$ later, respectively. The last $\mathrm{M}_{\mathrm{L}}>5$ event occurred in June $3 \mathrm{rd}$, with $\mathrm{M}_{\mathrm{L}} 5.1\left(\mathrm{M}_{\mathrm{W}}\right.$ 4.9). In a month, 30 earthquakes with $\mathrm{M}_{\mathrm{L}}>4.0$ were recorded, and of the total, about 2,500 events were located during the following three months (http://iside.rm.ingv.it/).

In Figure 1, the QRCMT solutions that we were able to compute are mapped; the colored dots represent other events belonging to this seismic sequence. All of the focal mechanisms were thrust, in some cases with different, but small, percentages of strike-slip components. In Table 1, the source parameters for all of the QRCMTs are reported. The recomputed depth is also included, even if for the QRCMT it can be considered as an approximate evaluation, overall for shallow earthquakes (depth $<10 \mathrm{~km}$ ), as in this case. The $\mathrm{M}_{\mathrm{W}}$ values we obtained are in very good agreement with those from other agencies, and they showed regular behavior with 


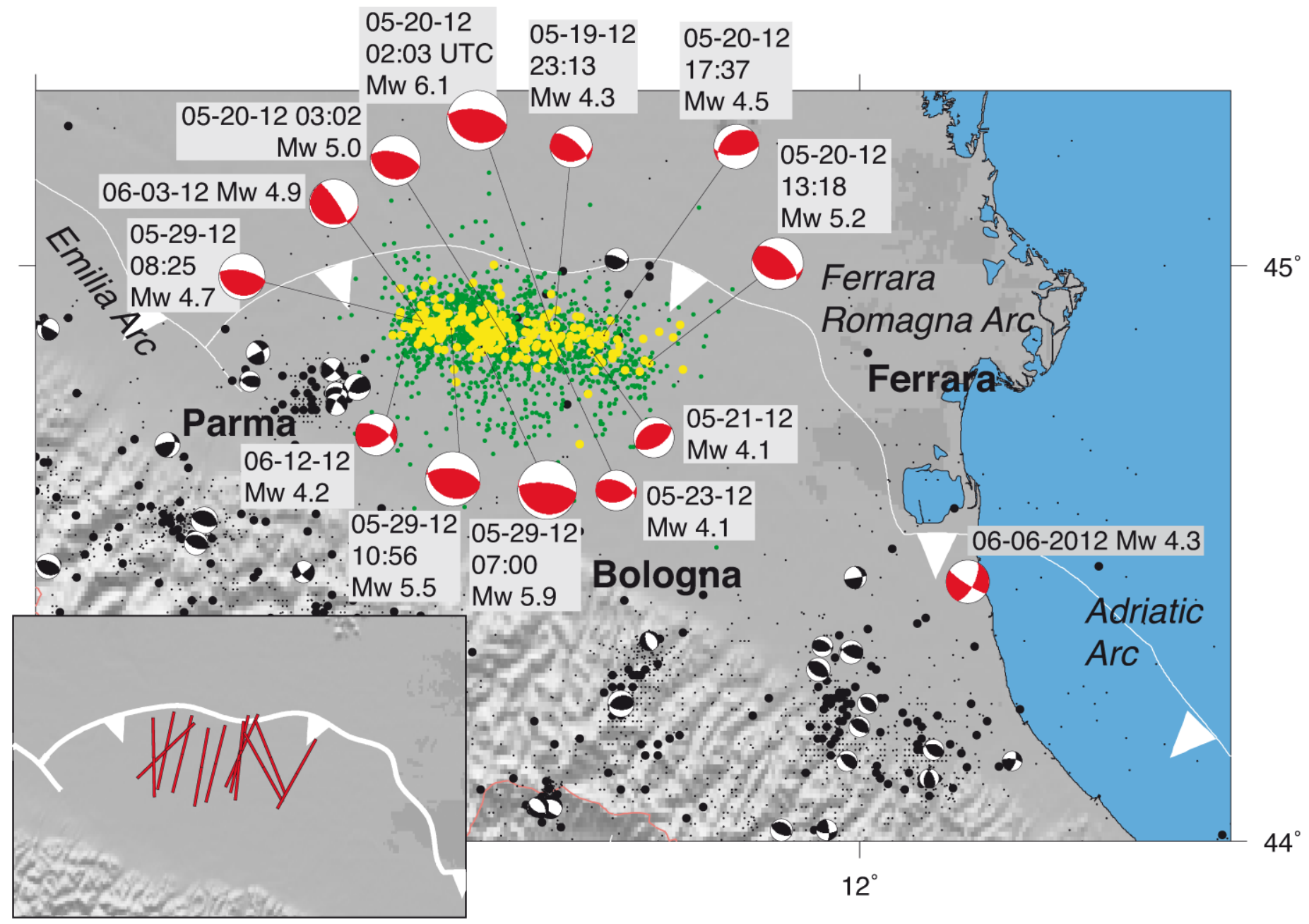

Figure 1. Map showing the QRCMTs (red, focal mechanisms) and their P axes (inset, lower left). Green, seismicity of seismic sequence with a M $<3.0$; yellow, seismicity of seismic sequence with $\mathrm{M} \geq 3.0$. The small black focal mechanisms are all RCMTs from the European Mediterranean catalog for seismicity before May 2012. Black dots (with dimensions proportional to magnitude), previous seismicity from http: / /iside.rm.ingv.it.

\begin{tabular}{|c|c|c|c|c|c|c|c|c|c|c|c|c|c|c|}
\hline Event ID & $\begin{array}{c}\text { Day } \\
\text { (yyyy-mm-dd) }\end{array}$ & $\begin{array}{c}\text { Time } \\
\text { (hh:mm:ss UTC) }\end{array}$ & $\begin{array}{l}\text { Latitude } \\
\left({ }^{\circ} \mathbf{N}\right)\end{array}$ & $\begin{array}{l}\text { Longitude } \\
\left({ }^{\circ} \mathrm{E}\right)\end{array}$ & $\begin{array}{l}\text { Depth } \\
(\mathrm{km})\end{array}$ & $M_{L}$ & $\mathrm{M}_{\mathrm{W}}$ & $\mathbf{M}_{0}(\mathrm{Nm})$ & $\begin{array}{c}\text { Strike } \\
1\end{array}$ & Dip & $\underset{1}{\text { Slip }}$ & $\begin{array}{c}\text { Strike } \\
2\end{array}$ & $\begin{array}{c}\text { Dip } \\
2\end{array}$ & $\underset{2}{\text { Slip }}$ \\
\hline 1 & $2012-05-19$ & $23: 13: 27$ & 44.90 & 11.26 & 13.6 & 4.1 & 4.29 & $3.37 \mathrm{e} 15$ & 85 & 32 & 50 & 310 & 66 & 112 \\
\hline 2 & $2012-05-20$ & 02:03:53 & 44.89 & 11.23 & 11.4 & 5.9 & 6.11 & $1.81 \mathrm{e} 18$ & 109 & 30 & 99 & 279 & 60 & 85 \\
\hline 3 & $2012-05-20$ & 03:02:50 & 45.05 & 11.17 & 14.1 & 4.9 & 5.05 & $4.60 \mathrm{e} 16$ & 103 & 27 & 89 & 284 & 63 & 91 \\
\hline 4 & $2012-05-20$ & $13: 18: 02$ & 44.83 & 11.49 & 10.0 & 5.1 & 5.18 & $7.25 \mathrm{e} 16$ & 100 & 37 & 64 & 312 & 57 & 109 \\
\hline 5 & $2012-05-20$ & $17: 37: 14$ & 44.88 & 11.38 & 12.9 & 4.5 & 4.52 & $0.76 \mathrm{e} 16$ & 235 & 43 & 72 & 79 & 50 & 106 \\
\hline 6 & $2012-05-21$ & $16: 37: 31$ & 44.85 & 11.35 & 10.0 & 4.1 & 4.13 & $1.93 \mathrm{e} 15$ & 243 & 37 & 92 & 60 & 53 & 89 \\
\hline 7 & $2012-05-23$ & $21: 41: 18$ & 44.85 & 11.36 & 11.9 & 4.3 & 4.13 & $1.96 \mathrm{e} 15$ & 77 & 43 & 63 & 292 & 52 & 113 \\
\hline 8 & $2012-05-29$ & 07:00:03 & 45.00 & 11.12 & 11.1 & 5.8 & 5.96 & $1.07 \mathrm{e} 18$ & 110 & 20 & 103 & 276 & 71 & 85 \\
\hline 9 & $2012-05-29$ & $08: 25: 51$ & 45.02 & 10.90 & 12.0 & 4.5 & 4.69 & $1.36 \mathrm{e} 16$ & 105 & 21 & 94 & 281 & 69 & 88 \\
\hline 10 & $2012-05-29$ & $10: 55: 57$ & 44.99 & 10.97 & 11.4 & 5.3 & 5.53 & $2.42 \mathrm{e} 17$ & 112 & 32 & 101 & 279 & 59 & 83 \\
\hline 11 & $2012-06-03$ & $19: 20: 43$ & 44.96 & 10.96 & 10.0 & 5.1 & 4.89 & $2.68 \mathrm{e} 16$ & 92 & 16 & 37 & 326 & 81 & 103 \\
\hline 12 & $2012-06-06$ & 04:08:31 & 44.45 & 12.26 & 25.4 & 4.5 & 4.34 & $4.00 \mathrm{e} 15$ & 28 & 66 & -10 & 122 & 81 & -156 \\
\hline 13 & $2012-06-12$ & $01: 48: 36$ & 44.88 & 10.89 & 13.7 & 4.3 & 4.19 & $2.37 \mathrm{e} 15$ & 56 & 52 & 39 & 299 & 60 & 135 \\
\hline
\end{tabular}

Table 1. Source parameters for the events of the Emilia sequence for which a QRCMT was computed. 
respect to the $M_{L}$, as we had already seen for the L'Aquila seismic sequence [Pondrelli et al. 2010].

Strong evidence for the stability of the QRCMTs is provided by a comparison with all of the available quick solutions, which is possible at the European Mediterranean Seismological Centre (EMSC) website, where all of the seismic moment tensors for the same earthquake are gathered into a dedicated database (http: / / www.emsc-csem.org/Earth quake/tensors.php), or through maps for the single events (e.g., http:/ / www.emsc-csem.org/Earthquake/ earthquake. php?id=267440\#map). For the May 20, 2012, M 5.9 event, solutions from USGS, Geofon (GFZ), Global CMT (HARV), GeoAZUR (AZUR) and California Poly Pomona (CPP) appear to be in strong agreement with our QRCMT, in terms of the focal mechanisms and $\mathrm{M}_{\mathrm{W}}$ values (named as INGV on the map and in the Table on the EMCS webpage). This similarity is consistent for all of the events of the sequence with magnitudes $>5.0$. For smaller magnitude earthquakes, the only possible comparison is with the time-domain moment tensor (TDMT) computed by the INGV (http: / / cnt.rm.ingv. it/tdmt.html) [Scognamiglio et al. 2009]. We used different stations and a signal characterized by a different frequency, although usually we have strong similarities [Scognamiglio et al. 2009], as for instance in the solutions for the May 20, 2012, 17:37 UTC, $\mathrm{M}_{\mathrm{L}} 4.5$ event: both the QRCMT and the TDMT show rotation towards the NW of the P axis (http:/ / cnt.rm. ingv.it/data_id_old//7222922570/map_dmt_review.pdf ).

The thrust mechanisms, as for those determined for the Emilia earthquakes, are in agreement with the compressive tectonic structures that belong to the Apennines and are buried below the Po Plain sediments [Boccaletti et al. 2004,
2011, and references therein], in particular with the fold and thrust structures that are commonly named as the Emilia Arc, the Ferrara-Romagna Arc and the Adriatic Arc (Figure 1, white toothed lines) [Pieri and Groppi 1981, Montone and Mariucci 1999, Carminati et al. 2010, Lavecchia et al. 2004, Scrocca 2006]. The shape of these arcs helps in the understanding of the variation in the P-axes directions of the QRCMT solutions (Figure 1, inset): major events show pure, low angle, thrust mechanisms, with a $\mathrm{P}$ axis pointing towards the north. Some aftershocks clearly rotate with respect to this dominant northwards direction; in particular, those pointing towards the NW that are located close to the NE-striking part of the buried thrust front (Figure 1). Most of the faults that populate the folds and thrusts buried beneath the Po Plain are high-angle structures, although there are also some low angle faults, in agreement with most of the QRCMT focal mechanisms. The seismic moment tensor of one more event, which occurred on June 6,2012 , is considered out of sequence, because it was located $100 \mathrm{~km}$ east of the principally struck region; it has been taken into account anyway, because it occurred along one of the tectonic structures related to those that were activated during the seismic sequence itself. It is pure strike-slip, and it can be interpreted as occurring at the crossing point of the Ferrara-Romagna Arc and the Adriatic Arc (Figure 1).

\section{QRCMT computation technique: automatic and rapidly revised solutions}

We obtained a robust rapidly revised solution for 13 earthquakes of the sequence (Table 2). All of these have been computed automatically previously, following a process that was activated by Alert emails, and was mainly structured into

\begin{tabular}{|c|c|c|c|c|c|c|c|c|c|c|c|c|c|}
\hline Event ID & Exp & Mrr & S.E. & Mss & S.E. & Mee & S.E. & Mrs & S.E. & Mre & S.E. & Mse & S.E. \\
\hline 1 & 15 & 2.51 & 0.52 & -2.39 & 0.28 & -0.12 & 0.31 & -1.12 & 0.32 & 2.0 & 0.50 & 0.59 & 0.19 \\
\hline 2 & 18 & 1.51 & 0.06 & -1.52 & 0.04 & 0.20 & 0.03 & -0.92 & 0.13 & 0.06 & 0.10 & 0.40 & 0.03 \\
\hline 3 & 16 & 3.39 & 0.31 & -3.84 & 0.18 & 0.44 & 0.17 & -2.59 & 0.31 & 0.66 & 0.31 & 1.09 & 0.12 \\
\hline 4 & 16 & 6.33 & 0.18 & -5.39 & 0.17 & -0.94 & 0.17 & -1.22 & 0.57 & 2.84 & 0.50 & 2.83 & 0.16 \\
\hline 5 & 16 & 0.75 & 0.10 & -0.62 & 0.07 & -0.14 & 0.05 & 0.15 & 0.09 & -0.14 & 0.09 & -0.25 & 0.05 \\
\hline 6 & 15 & 1.80 & 0.16 & -1.46 & 0.13 & -0.34 & 0.13 & 0.43 & 0.39 & 0.27 & 0.39 & -0.87 & 0.13 \\
\hline 7 & 15 & 1.75 & 0.31 & -1.92 & 0.22 & 0.17 & 0.21 & -0.25 & 0.36 & 0.61 & 0.61 & 0.17 & 0.10 \\
\hline 8 & 18 & 0.63 & 0.02 & -0.66 & 0.02 & 0.03 & 0.01 & -0.83 & 0.08 & 0.07 & 0.04 & 0.16 & 0.01 \\
\hline 9 & 16 & 0.80 & 0.22 & -0.96 & 0.13 & 0.16 & 0.13 & -0.99 & 0.31 & 0.19 & 0.28 & 0.26 & 0.09 \\
\hline 10 & 17 & 2.07 & 0.12 & -2.04 & 0.08 & -0.04 & 0.06 & -1.13 & 0.19 & 0.05 & 0.21 & 0.59 & 0.05 \\
\hline 11 & 16 & 0.88 & 0.15 & -0.84 & 0.09 & -0.04 & 0.16 & -1.26 & 0.33 & 2.14 & 0.43 & 0.52 & 0.10 \\
\hline 12 & 15 & -0.27 & 0.58 & -2.97 & 0.35 & 3.24 & 0.42 & -1.78 & 0.42 & 0.23 & 0.54 & -1.78 & 0.20 \\
\hline 13 & 15 & 1.40 & 0.40 & -1.95 & 0.25 & 0.55 & 0.23 & -0.30 & 0.22 & 1.71 & 0.50 & -0.19 & 0.14 \\
\hline
\end{tabular}

Table 2. Exponent and moment tensor elements, together with their standard errors. 


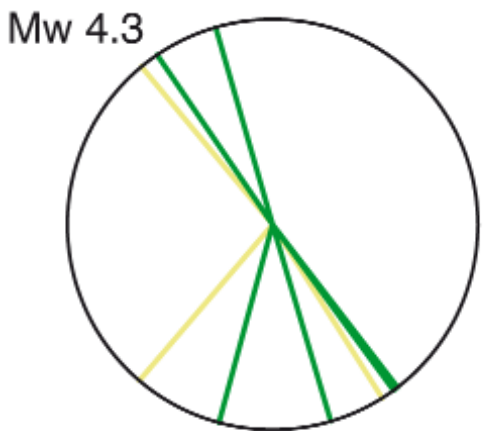

2012-05-19 23:13 UTC

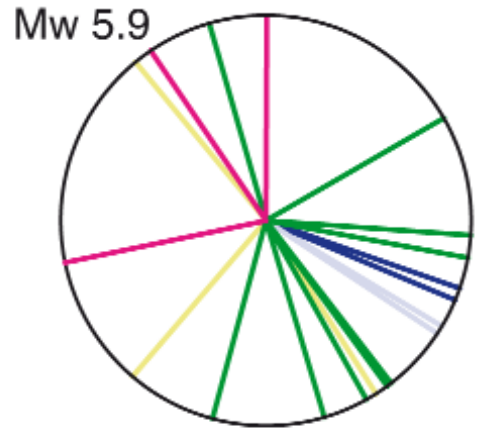

2012-05-20 02:03 UTC

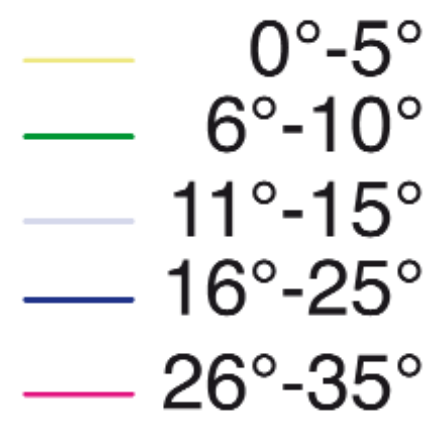

$26^{\circ}-35^{\circ}$

Figure 2. Station distribution around the epicenter for the May 19, 2012, $M_{L} 4.1$ and May 20, 2012, $M_{L}$ 5.9 events, to compare the station distribution and availability a short time after the event with changing magnitude. Different colors represent different station-epicenter distances, in degrees.

a data-managing part and a computational part [Pondrelli et al 2012]. QRCMT solutions obtained automatically are successively reviewed by an operator, who checks the waveform selection and reliability of the fits and the quality of the centroid location. If necessary, the operator can fix the epicenter coordinates and depth. Usually, a repeated inversion over different depths values is also carried out, mainly when working with shallow events, as in this case, to find the centroid depth that generates the best fit between the waveforms and the synthetic seismograms. We have been working on this procedure since the L'Aquila sequence, as we are confident that the QRCMT solutions can have a relevant contribution to the rapid assessment of earthquake scenarios. During this Emilia sequence, we tested some of the positive results.

All of the solutions were published on the web within $1 \mathrm{~h}$ of the earthquake occurrence. This timing arises from four phases: (i) the Alert email; (ii) data recovery; (iii) computational time; and (iv) visual inspection and revision. On average, during this sequence, computations took 7-8 min (including seismogram recovery; e.g. points (ii) and (iii) above) which is the typical timing we observed for isolated moderate magnitude events. The manual revision took from $10 \mathrm{~min}$ to $20 \mathrm{~min}$ (e.g., point (iv)); the rest of time was mainly taken up by communication and network traffic jams (e.g., point (i)). Indeed, for the May 20, 2012, $M_{L} 5.9$ and 29 May, 2012, $M_{L} 5.8$ events, and for the successive aftershocks, on average, the whole of the process took between $70 \mathrm{~min}$ and $90 \mathrm{~min}$, which were mainly spent waiting for the Alert email and the data recovery. While there are technical solutions to shorten the seismogram time collection - and we are testing some of these - we still did not find any solution to cut down the Alert time. We receive Alert emails from INGV for Italy and from EMSC for the rest of Mediterranean region. During the Emilia sequence, we received the Alert email after 8$10 \mathrm{~min}$ for all of the events, but for the strongest one, we had to wait more than $20 \mathrm{~min}$.

If the QRCMT publishing time cannot be shortened, we prefer to focus on the high quality of our solutions. Taking into account that we commonly study low to moderate (between 4.0 and 5.5) magnitude events, we choose to manu- ally revise the solutions before the web publication, overall considering that this part of the procedure takes about the same time that we wait for the Alerts. The manual revision often solves all of the data instabilities that affect mainly the QRCMT computation of low to moderate magnitude events, due to seismogram selection, to better satisfying a good azimuthal distribution of stations, or to choose the best filtering in relation to the magnitude and epicenter-station distance. An example of different conditions of station azimuthal distributions combined with epicenter-station distances is shown in Figure 2. For the minor event with $M_{L} 4.1$ $\left(\mathrm{M}_{\mathrm{W}} 4.3\right)$ of May 19, 2012, that preceded the mainshock, the azimuthal distribution is relatively uneven, although all of the stations have a real regional distance of between 1 and 10 degrees (Figure 2). On the other hand, the azimuthal distribution for the main shock is better, because it was completed by some farther away stations that cover the western back azimuths. This better homogeneity around the event is guar-

\begin{tabular}{ccccc}
\hline $\begin{array}{c}\text { Date } \\
(\mathbf{y y y y - m m - d d})\end{array}$ & $\begin{array}{c}\text { Time } \\
(\mathbf{h h : m m : s s} \mathbf{U T C})\end{array}$ & $\begin{array}{c}\mathbf{M}_{\mathbf{W}} \\
\text { Automatic } \\
\mathbf{r m s}\end{array}$ & $\begin{array}{c}\text { Revised } \\
\mathbf{r m s}\end{array}$ \\
\hline $2012-05-19$ & $23: 13: 27$ & 4.29 & 0.765 & 0.324 \\
\hline $2012-05-20$ & $02: 03: 53$ & 6.11 & 0.250 & 0.150 \\
\hline $2012-05-20$ & $03: 02: 50$ & 5.05 & 0.444 & 0.186 \\
\hline $2012-05-20$ & $13: 18: 02$ & 5.18 & 0.646 & 0.095 \\
\hline $2012-05-20$ & $17: 37: 14$ & 4.52 & 0.729 & 0.274 \\
\hline $2012-05-21$ & $16: 37: 31$ & 4.13 & 0.920 & 0.288 \\
\hline $2012-05-23$ & $21: 41: 18$ & 4.13 & 0.737 & 0.265 \\
\hline $2012-05-29$ & $07: 00: 03$ & 5.96 & 0.314 & 0.127 \\
\hline $2012-05-29$ & $08: 25: 51$ & 4.69 & 0.683 & 0.298 \\
\hline $2012-05-29$ & $10: 55: 57$ & 5.53 & 0.306 & 0.091 \\
\hline $2012-06-03$ & $19: 20: 43$ & 4.89 & 0.613 & 0.367 \\
\hline $2012-06-06$ & $04: 08: 31$ & 4.34 & 0.741 & 0.378 \\
\hline $2012-06-12$ & $01: 48: 36$ & 4.19 & 0.718 & 0.370 \\
\hline
\end{tabular}

Table 3. Information on the automatic and rapidly revised solutions. 


\section{May 20th MI 5.8}
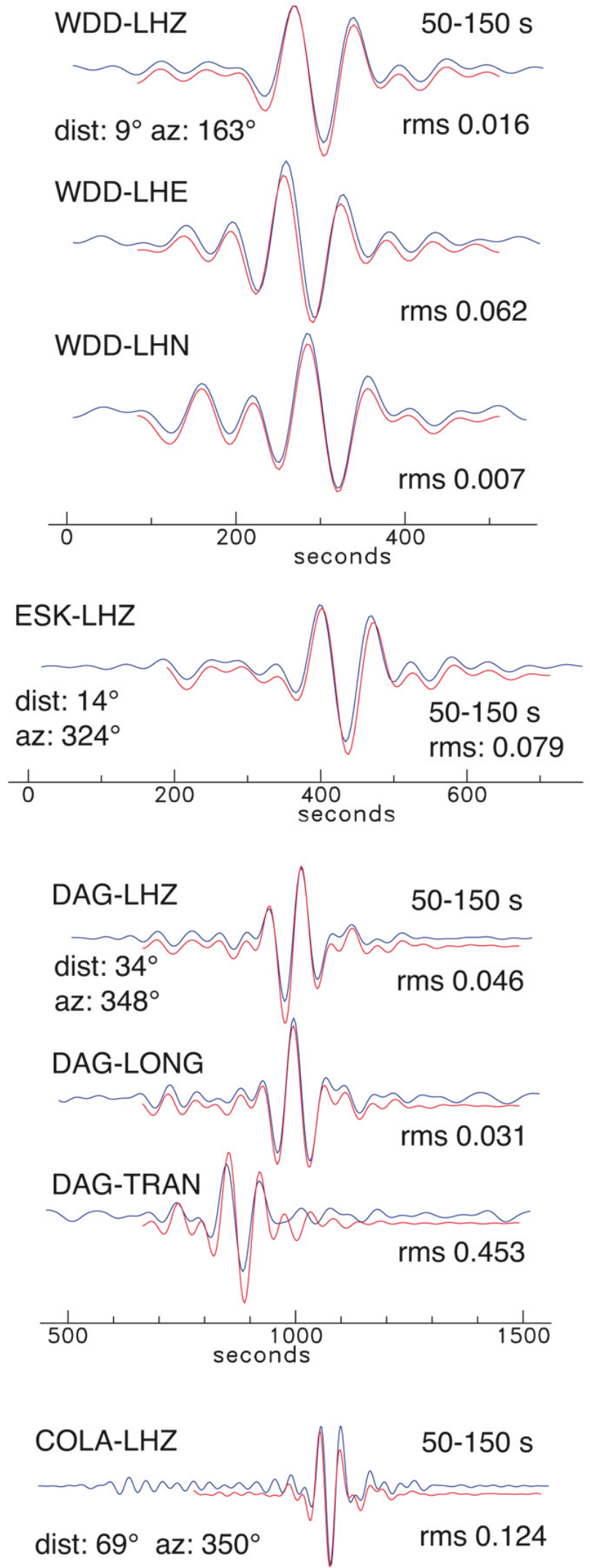

dist: $69^{\circ}$ az: $350^{\circ}$

0.124

\section{May 19th Ml 4.1}

AQU-LHZ

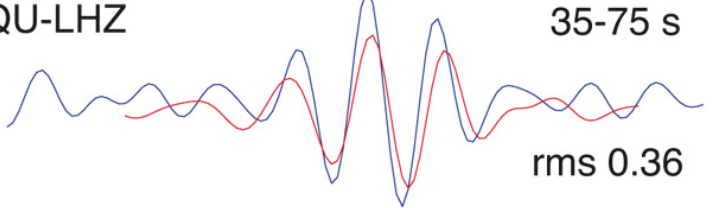

AQU-LHE
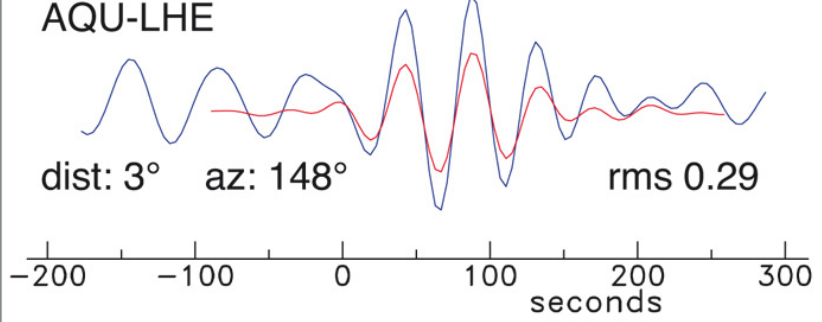

VSL-LHZ

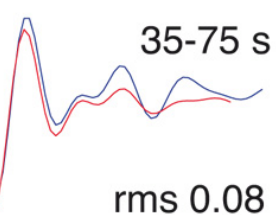

$35-75 s$

rms 0.08

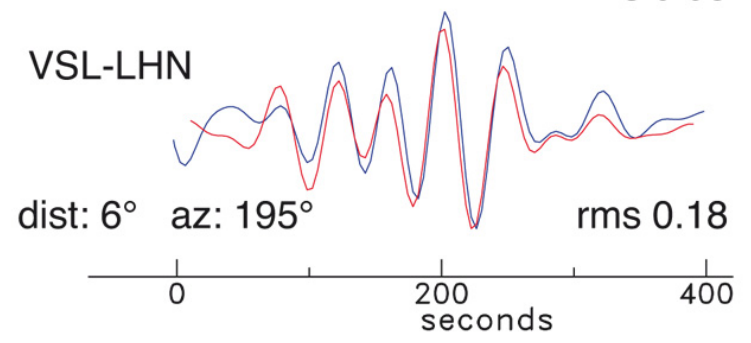

Figure 3. Examples of waveforms (blue) and synthetics (red) used for the QRCMT computations. Left: examples for the May 20, 2012, $\mathrm{M}_{\mathrm{L}} 5.8$ event. Right: examples for the May 19, 2012, $M_{L} 4.1$ event.

anteed by the greater magnitude, with a better signal-tonoise ratio at greater distance, which allows lower filtering. This is demonstrated also by some of the examples of comparisons between data and synthetic waveforms in Figure 3, where for the same distance, we need different filtering to obtain the best signal-to-noise ratio with respect to the best fit. For the mainshock, a cut off between $50 \mathrm{~s}$ and $150 \mathrm{~s}$ is enough, while for lower magnitude events, we have to filter the signal between $35 \mathrm{~s}$ and $75 \mathrm{~s}$, which obtains a noisier waveform, but a good fit too (Figure 3).

What we observed during the Emilia seismic sequence through checking all of the automated procedure timing and results is that we could have published the automatically computed QRCMTs for the events with magnitudes $>5.5$. Table 3 gives the root mean square (r.m.s.) values computed on the entire set of seismograms that we inverted, for each solution, before and after the manual revision. All of the events with magnitudes $>5.5$ (Table 3 , with gray back- 
Automatic QRCMT

$2012 / 05 / 20$

02:03

$2012 / 05 / 29$

07:00

$10: 55$
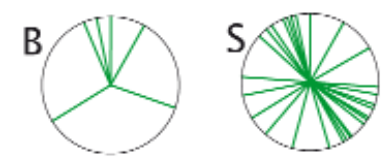

ns:6 nc: 12

ns:28 nc: 75
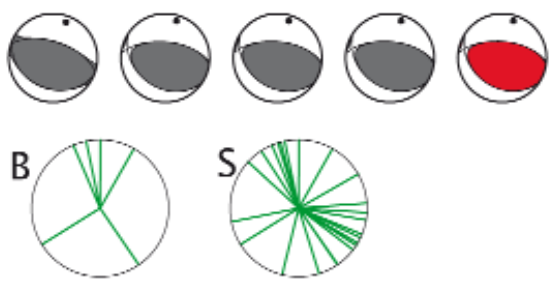

ns:6 nc: 7

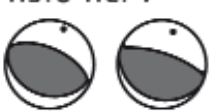

ns:24 nc: 60
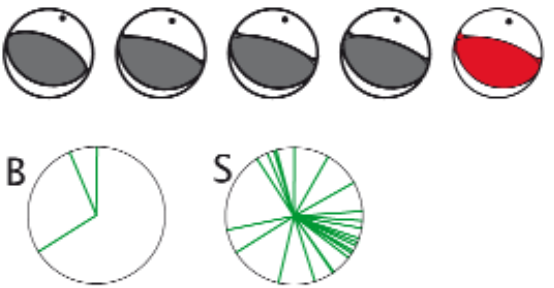

ns:5 nc: 5
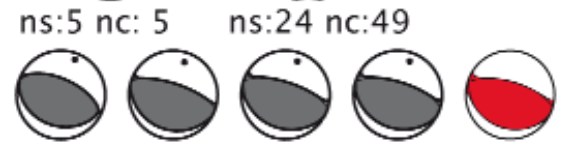

Revised QRCMT
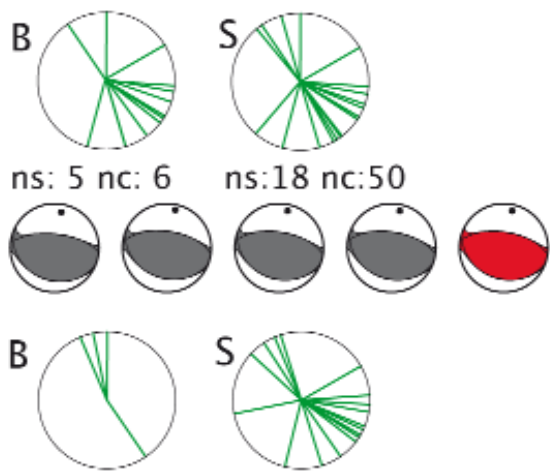

ns: 4 nc: 4 ns:20 nc:50
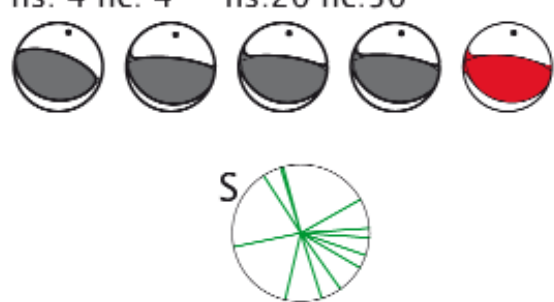

ns: 12 nc: 24
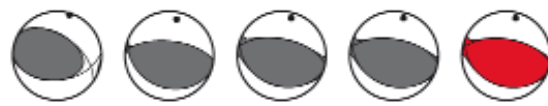

Figure 4. Comparison between the automatic and revised conditions for the three events of the seismic sequence with M >5.5. Upper parts: For each QRCMT, the station distribution is shown around the epicenter for surface (S) and body (B) waves, and the number of stations (ns) and number of components (nc) used in the inversion. Lower parts: All five moment tensors are shown, as obtained for each iteration of the inversion, where the red one is the final solution.

ground) show r.m.s. for the automatic solution that are within the criteria that match with a stable solution (e.g., $<0.4)$. Other criteria needed are also respected: at least the data from three stations that were azimuthally well distributed around the epicenter (Figure 4); a focal mechanism that was stable over five iterations (Figure 4); a difference between initial and final coordinates $<0.3^{\circ}$; and a small non-doublecouple component [Pondrelli et al. 2006]. These characteristics allowed these solutions to be considered for immediate web publication, in 30-45 min from event occurrence. This result, which will drive our choice for the future, is valid only for strong Italian earthquakes, where the aforementioned conditions are satisfied: sufficient data availability in terms of distance and azimuthal distribution around the epicenter. For smaller magnitude events, the manual revision of the seismic moment tensor solutions is still fundamental. However, finding the technical solutions for the filtering with respect to the station distance and the data availability would allow a lowering of the magnitude threshold for automatic immediate QRCMT publication, at least for Italy.

\section{Conclusions}

The QRCMT solutions we computed for large to moderate magnitude events during the Emilia 2012 sequence are in agreement with the seismotectonic setting of the shaken region and with the solutions distributed by other agencies. We determined the seismic moment tensors for 13 events, and for some of these we obtained a very stable QRCMT solution, already from the automated system of recovery and the computations developed in house over recent years. The sequence was an important test to demonstrate that for events that occur in Italy with $\mathrm{M}>5.5$ our automated system for QRCMT computation works very well, and we can assume for the future to immediately publish the automated solutions on the web, without any manual revisions.

Acknowledgements. We thank the Data Centers of MedNet, Geofon and the GSN, starting from the people who take care of the instruments at the station sites, to those who make the data available on the web. We are grateful to Paolo Boncio and to an anonymous reviewer for important suggestions and comments on our original manuscript. Plots were made using the Generic Mapping Tools, version 4.2.1 [www.soest.hawaii.edu/gmt; Wessel and Smith 1998]. All of the QRCMT solutions are commonly published a short time after the event occurrence on the dedicated web pages http:/ / autorcmt.bo.ingvit/ quicks.html, and on the EMSC web pages.

\section{References}

Boccaletti, M., M. Bonini, G. Corti, P. Gasperini, L. Martelli, L. Piccardi, C. Tanini and G. Vannucci (2004). Seismotectonic Map of the Emilia-Romagna Region, 1:250000. Regione Emilia-Romagna - CNR.

Boccaletti, M., G. Corti and L. Martelli (2011). Recent and active tectonics of the external zone of the northern Apennines (Italy), Int. J. Earth Sci., 100, 1331-1348.

Carminati, E., D. Scrocca and C. Doglioni (2010). Compaction-induced stress variations with depth in an active 
anticline: northern Apennines, Italy, J. Geophys. Res., 115, B02401; doi:10.1029/2009JB006395.

Ekström, G., J. Tromp and E.W.F. Larson (1997). Measurements and global models of surface wave propagation. J. Geophys. Res. 102, 8137-8158.

Lavecchia, G., N. Boncio, N. Creati and F. Brozzetti (2004). Stile strutturale e significato sismogenetico del fronte compressivo padano-adriatico: dati e spunti da una revisione critica del profilo Crop 03 integrata con l'analisi di dati sismologici, B. Soc. Geol. Ital., 123, 111-125.

Montone, P., and M. Mariucci (1999). Active stress along the NE external margin of the Apennines: The Ferrara Arc, northern Italy, J. Geodyn., 28, 251-265.

Pieri, M., and G. Groppi (1981). Subsurface geological structures of the Po Plain, CNR, Progetto Finalizzato Geodinamica, Pubblicazione 414.

Pondrelli, S., A. Morelli, G. Ekström, S. Mazza, E. Boschi and A.M. Dziewonski (2002). European-Mediterranean regional centroid-moment tensors: 1997-2000, Phys. Earth Planet. Int., 130, 71-101.

Pondrelli S., A. Morelli and G. Ekström (2004). EuropeanMediterranean regional centroid moment tensor catalog: solutions for years 2001 and 2002, Phys. Earth Planet. Int., 145, 127-147.

Pondrelli, S., S. Salimbeni, G. Ekström, A. Morelli, P. Gasperini and G. Vannucci (2006). The Italian CMT dataset from 1977 to the present, Phys. Earth Planet. Int., 159, 286-303; doi:10.1016/j.pepi.2006.07.008.

Pondrelli, S., S. Salimbeni, A. Morelli, G. Ekström and E. Boschi (2007). European-Mediterranean regional centroid moment tensor catalog: solutions for years 2003 and 2004, Phys. Earth Planet. Int., 164, 90-112.

Pondrelli, S., S. Salimbeni, A. Morelli, G. Ekström, M. Olivieri and E. Boschi (2010). Seismic moment tensors of the April 2009, L'Aquila (central Italy) earthquake sequence, Geophys. J. Int.; doi: 10.1111/j.1365-246X.2009. 04418.x

Pondrelli, S., S. Salimbeni, A. Morelli, G. Ekström, L. Postpischl, G. Vannucci and E. Boschi (2011). EuropeanMediterranean regional centroid moment tensor catalog: solutions for 2005-2008, Phys. Earth Planet. Int., $185,74-81$.

Pondrelli, S., P. Perfetti and P. Danecek (2012). Pypaver: automazione del calcolo dei Quick RCMT con Python, Rapporti Tecnici INGV, submitted.

Scognamiglio, L., E. Tinti and A. Michelini (2009). Real-time determination of seismic moment tensor for Italian region, B. Seismol. Soc. Am., 99, 2223-2242; doi:10.1785/ 0120080104.

Scrocca, D. (2006). Thrust front segmentation induced by differential slab retreat in the Apennines (Italy), Terra Nova, 18, 154-161.

Wessel, P., and W.H.F. Smith (1998). New improved version of the generic mapping tools released, Eos Trans. AGU, $79,579$.

Woodhouse, J.H., and A.M. Dziewonski (1984). Mapping the upper mantle: three dimensional modelling of earth structure by inversion of seismic waveforms. J. Geophys. Res., 89, 5953-5986.

\footnotetext{
*Corresponding author: Silvia Pondrelli, Istituto Nazionale di Geofisica e Vulcanologia, Sezione di Bologna, Bologna, Italy; email: silvia.pondrelli@bo.ingv.it.

(C) 2012 by the Istituto Nazionale di Geofisica e Vulcanologia. All rights reserved.
} 